\title{
Applications of system dynamics modelling to computer music*
}

\author{
IAN WHALLEY \\ The University of Waikato, Private Bag 3105, Hamilton, New Zealand \\ E-mail: musik@waikato.ac.nz \\ Based on a composer's psycho-acoustic imagination or \\ response to music, system dynamics modelling and \\ simulation tools can be used as a scoring device to map \\ the structural dynamic shape of interest of computer \\ music compositions. The tools can also be used as a \\ generator of compositional ideas reflecting thematic \\ juxtaposition and emotional flux in musical narratives. \\ These techniques allow the modelling of everyday \\ narratives to provide a structural/metaphorical means of \\ music composition based on archetypes that are shared \\ with wider audiences. The methods are outlined using \\ two examples.
}

\section{INTRODUCTION}

The reasons for looking to system dynamics tools to model the dynamic experience of computer music are varied. Initial work explored alternative methods of scoring in the idiom (Whalley 1999a). This was extended to address concerns about a diminishing sense of music as a dramatic art in much current computer music (Whalley 1999b). Finally, the tools were used to attempt to bridge the experiences of everyday life and computer music composition, by addressing the dislocation of computer music from potentially wider audiences (Bridger 1993, Milicevic 1998, Tanzi 1999) through modelling the interplay of structure and metaphor in music. This paper summarises the sequence of applications.

There are two assumptions made throughout the paper. First, that the creation and control of dramatic tension through thematic juxtaposition is a worthwhile artistic goal in narrative art forms. Second, that musical communication with audiences outside the academy based on common experiences is a worthwhile pursuit in academic computer music practice.

For the sake of example, the focus here is largely on acousmatic forms of computer music (Smalley 1997). The methods outlined here could also be used to generate music based on other styles, or combinations of styles.

\section{PROBLEMS OF MODELLING COMPUTER MUSIC EXPERIENCE}

A characteristic of acousmatic music is that rather than being referenced to instrumental performance gestures,

\footnotetext{
* From the ICMC 2000 Workshop on Cognition and Perception Issues in Computer Music.
}

it often reflects more slowly evolving environmental gestures (Smalley 1997). Further, the dislocation of sound source from performance and tonality often results in context rather than external reference being able to define the musicality and authenticity of sound (Menezes 1997), and a sound object's location is often intended to be established within a piece. This external to internal shift is also significant because works are understood and played in the imagination, rather than against an external theoretical construct (Rudy 1999). This presents both structural and metaphorical problems in scoring works, and problems in linking works to shared experiences as a basis for communication.

Composers often attempt to score computer music in visual equivalents. This largely involves drawings that show pitch on the vertical axis and events on the horizontal axis. The microtonal nature of many scores means that only broad gestures can be approximated. Often these scores are of little use except as a broad guide to the events in the work, and they serve as a guide to frequency spectrum listening.

Similar attempts have been trailed using spectrum analysis (Cogan 1984). Software-based microtonal synthesizer generators such as Metasynth use a similar approach as a basis for composition, but also add colour to indicate left and right spatialisation, and brightness to indicate volume.

None of these methods are able to fully approximate the music. While identifying sections and form, they often fail to identify the temporal dynamic of a work: put another way, music is a dynamic art that relies on the interplay of many parts, and the graphic method of representation is static.

A compounding factor is that computer music composers generally work directly in sound, bypassing the need for a score. The 'score' is likely to be a set of sketches and notes for a piece that are largely inaccessible to all but the composer and a few initiates. The listening experience of the music is often quite different from these sketches, and different from the composer's techniques of arriving at particular sounds and sections of a composition.

Why attempt to model this new art form? As a composer partly in this idiom, one recognises the increasing gap between the experience of composing and the listening experience, particularly of a non-initiated audience. Although not a problem unique to this style, compositional intention and the results from a listening 
perspective often differ far more significantly here than in traditional pitch/duration idioms. A model that approximates any aspect of reception rather than generation may then aid in bridging this gap and aid composition as communication.

To fully capture a listener's experience in a score is a daunting task. Music is partly a metaphorical art form and individual responses to a work may vary widely, unless the composer has built the piece on a narrative that can be related (Landy 1994), or something that lays out the intention (Norman 1994). Besides, metaphorical musical communication presents unique problems (Camurri 1998, Zannos 1999) and needs specific attention: issues that are dealt with in later sections.

What can be represented in purely structural terms? The dynamic flow of events that underpins and is an integral part of the structure of a work presents many possibilities. Modelling the dialectic between structure and event within a temporal framework gives a composer one indication of the way a work may be received. For computer music, this approach to modelling is of further significance, since works, being largely selfreferencing, play out their structural dynamic through first establishing a base level of activity and material against which later events are played off.

The province of system dynamics is the modelling and simulating narratives, and specifically closed systems. As such, the approach provides tools to help come to terms with the dynamic structural experience of computer music, in contrast to conventional scoring methods.

\section{SYSTEM DYNAMICS}

System dynamics developed from the pioneering work of Forrester (1961). The methods have been made popular through the development of the personal computer and commercial modelling packages such as Vensim, Powersim and Stella. The focus is on simulating narratives based on influence diagrams, stocks, flows, and feedback loops (Coyle 1993). These models have been applied to a variety of topics from the sciences, to management (Roberts 1991), social sciences, and to a lesser degree, the arts. They allow the modelling of hard narratives based on actual figures, or soft narratives based on numbers assigned to qualitative scales.

System dynamics software modelling relies on a three-step process: drawing the structure of the narrative or situation being examined; making assumptions about the nature of the relationships between parts of the structure; and running the model in compressed time to illustrate the interaction of various parts. A main significance of these tools, in addition to checking assumptions about the situation being studied, is that they can be used to run 'what if' scenarios to test different approaches to problems. Applied to dramatic art, for example, one can use current software to simulate the narrative structure of plays to show different plot outcomes.

In the model (figure 1) built using Stella software, the double lines with an arrow represent the direction of flows of information (like verbs). A box is an amount or stock of something (like a noun). The single arrow lines illustrate feedback or influence connections. The 'clouds' indicate zero activity. Relationships between parts are influenced by adding either graphs or formulas into the circles in the diagram to reflect assumptions made. This takes place 'behind the scenes' in the software by entering a lower level.

Once assumptions are added, the narrative can then be simulated in any time frame. Output is graphed based on any part of the model selected. This process allows the user to trial several strategies by altering the driving formulas. Graphed outputs provide the results of the interplay between parts (figure 4 gives an example), or the behaviour of a single part.

\section{STRUCTURAL MODELLING OF MUSIC}

The link between system dynamics modelling/simulation and dynamics musical structural experience is illustrated in recent work (Whalley 1999a, b).

Music is a time-based art form grounded in the experiential flow of events and relationships, similar to other narrative art forms. For example, in everyday dramas we repeatedly witness variation on the narrative patterns of introduction, complication, climax and resolution (a dynamic shape of interest). Abstract music, as narrative, deals with a similar dialectic, except it is played out not through verbal/visual discourse, but through aural/physical discourse. Although both are kinetic art forms, the difference is that stories deal with the explicit; and music is the province of the implicit. A sensual rather than conceptual art form, its province is persuasion and seduction rather than opinion and reason.

Like most dramatic narrative art forms, the classic dynamic shape of interest in most large-scale Western art music is developed so that the climax is about twothirds to three quarters the way through. This is worked out within the framework of introduction, variation, contrast or development, and recapitulation. Of course, this is by no means the only approach to controlling narrative tension; the example is used here to illustrate the principle of dynamic control.

The control of the structural dynamic of musical works is based on the manipulation of unity and variety of thematic material: a cornerstone of the development of conventional composition technique in music. Without a systematic and explicit way of illustrating this in real time, acquiring this skill in computer music is usually by trial and error. This is why a modelling process based on structural listening rather than generation holds significant possibilities: what graphically may be interesting through a conventional scoring method often does not equate to psycho-acoustic response. 
This begs the question of 'which listener' and 'listening to what'. The quality of listening can depend on the level of attentiveness and the knowledge of music brought to the situation. What people listen to can vary widely, regardless of attention.

In this light, the most realistic and substantial use of system dynamics tools is as a composition aid through modelling a composer's psycho-acoustic perception of their works, revealing aural dynamic intention. This is reflected in figures 1 and 2, which model a composer's perception of how they might hear a work, using three themes as inputs to a structure. A limitation is assuming that all listeners will be as fully cognisant and musically attentive and as informed as the composer having completed the work. This is the assumption many composers have made historically, although audiences may arrive at this depth of understanding by repeated listening to a composition.

Figure 1 maps the dynamic shape of interest of the work (right-hand side) based on unity/variety input and manipulation (left-hand side) as an abstract of the music. This allows composers to check their perceptions against other's experiences of their work, since system dynamics models allow 'flight simulator' interfaces through which listeners can alter the simulated outcomes based on their perception of a work.
The model here begs further explanation of the musical components. The two main drivers in any music that are built into this model are the tension between unity and variety. To paraphrase Pressing (1993: 10522 ), they are based on two main types of change, or stasis if they are continued or repeated. Rearrangement change occurs when time is expressed through motion or changes of position in unchanging sound objects, for example, through notes or recurring sound complexes. Attribute change occurs when time is expressed through alterations in the attributes of sound objects, such as parametric alterations in the qualities of a sound object.

The model of structure proposed (figure 1) is based on some grounding assumptions. First, that music as dynamic structure is a representation of personal experience of time (Imberty 1993); second, that this experience is only knowable through the perception of sound events (Kramer 1988); and finally, that the modelling of these events interactively in real time will approximate the experience. In these terms, by modelling statement, repetition and variation in the context of the dynamic interplay between unity and variety, climax and resolution. The dynamic interactive contribution of the composition's parts can be revealed.

The structure (figure 1) is similar to psychological models of happiness (McHugo 1992). The detail and

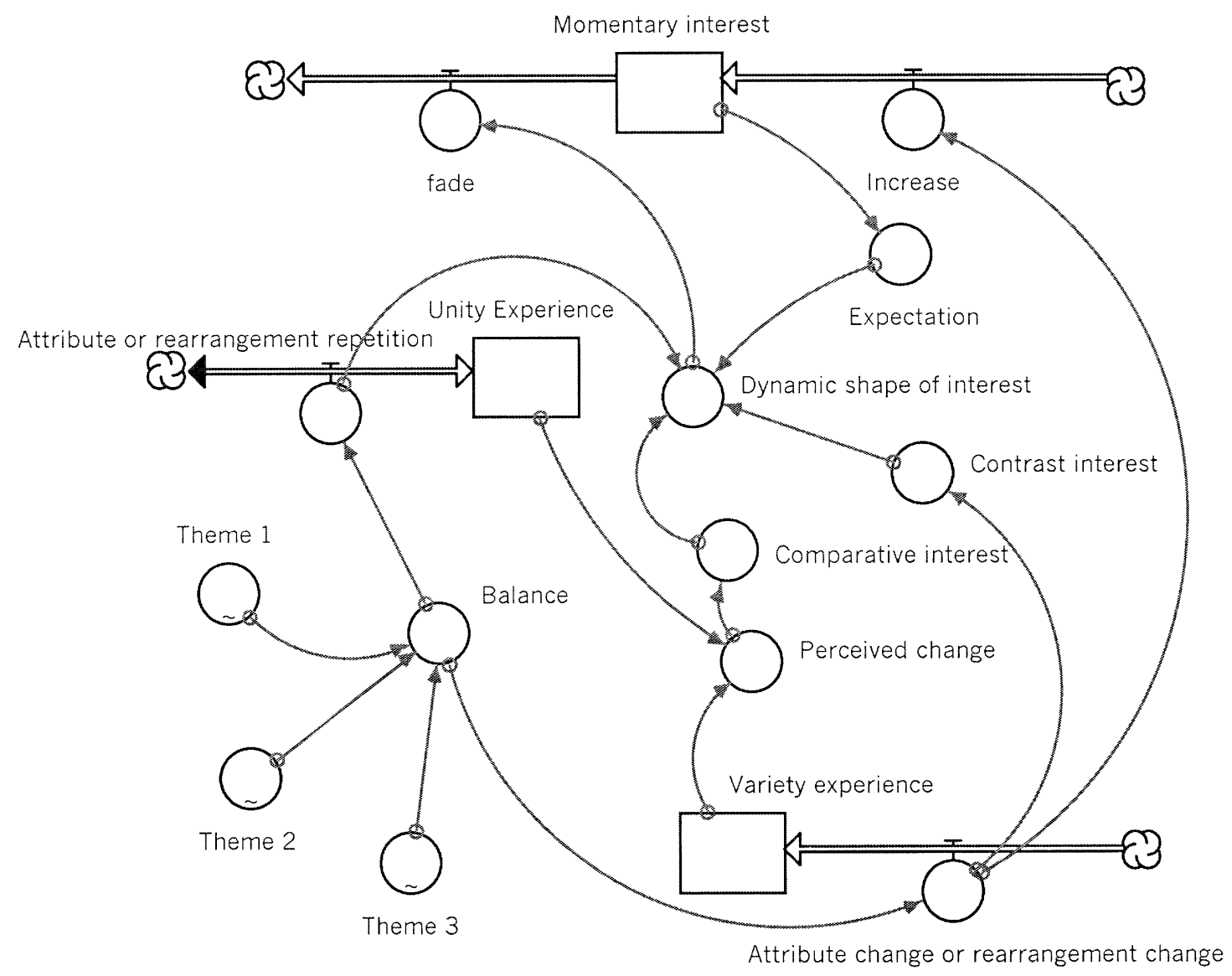

Figure 1. A system dynamics model of computer music structure. 
internal dynamic established in the relationship between parts is unique to music. The dynamic shape of interest is the end for the structural aspect of the flow of events in the model. The assumption is a perfect correlation between this and the contour of tension and relaxation in the piece, through adding driving formulas that accurately reflect psycho-acoustic intention/response in the composition. The structure and driving formulas may then be unique to each composition.

The right-hand side of the diagram (figure 1) also maps the adaptation dynamic, or the way change or rearrangement provides interest but also partly undermines the overall dynamic shape. For example, if many events happen suddenly to create excitement successively, they contribute to momentary interest and create increasing expectation for more of the same. This has a negative impact on the overall dynamic shape of interest.

Entering an abstract of the music into the model in the thematic drivers relies on composers being able to auralise individual thematic elements of the composition in the first instance as they would do traditionally, or enter them in when a composition is completed. A parallel is an author being able to plot a story imaginatively before setting words to paper. On the model (figure 1), this is done by entering information into the thematic inputs to Balance. Graphs are drawn for each theme so that each time frame (figure 2) is decided based on what musical information proceeded it: whether information is the same or different relative to what has happened before, to what degree, and what it may anticipate (Franks 2000).

Thematic inputs indicate a contribution to either unity or variety at any given interval through being either a negative or positive figure, with zero allowing for no contribution (no theme present). In this example, the piece is 185 seconds long, and is mapped at five-second intervals. Any definition can be set, and the entry lines can be continuous rather than staged. This allows rapid entry of information.

Not all themes will be present at the same time, and different clusters are likely to be significantly present at some stages rather than others. Through this method, one can quickly see how themes contribute to overall unity/ variety. Although the example (figure 1) allows for three main thematic elements, any number could be added here.

\section{THEMATIC JUXTAPOSITION}

Up to this point, the approach relies on composers taking a thematic approach to generating computer music, yet makes no assumptions about what themes may be made up of in terms of auditory material, or how they may relate to each other. In initially linking system dynamics to computer music, it became clear that although useful, it failed to illustrate how the creation and control of narrative tension through thematic juxtaposition was at the basis of many western narrative art works.

For example, the themes in figure 1 may be very similar, and one may end up with a false notion of the overall structural dynamic of the work. An analogy would be a dull story where all the characters are flawless, never get into difficult situations, and simply chat endlessly; yet the bustle of the conversation giving the impression of structural tension in the narrative.

Historically, strong narratives are made up of highly contrasting material that is played out within a controlled dynamic shape, such as the dialectic between protagonist and antagonist in plays from the Western classic dramatic tradition. In traditional tonal music, this contrasting tension is reflected in tonic/dominant polarity, or the contrasts between first and second subjects in classical sonata form, for example.

\section{EVERYDAY NARRATIVES TO MUSIC}

The technique of thematic juxtaposition found in literature is the basis of many narratives we encounter in daily life, archetypes (Senge 1992: 378-90) that can be modelled and simulated using system dynamics tools.

These narratives provide the basis of a generative thematic approach to computer music composition through linking emotional codes expressed in music to thematic drivers in the models. This method provides a way of making connections to wider audiences who share common points experiences with the narrative and emotional dynamic being manipulated, in much the same way a play can reflect shared generic or specific experience.

Using this approach allows computer music composers to deal with the intertextural nature of sound as cultural metaphor, that a spectromorphology approach neglects (Smalley 1997: 109-10). The ideas are illustrated in one example in the remaining sections.

In figure 3 , the example narrative being modelled is a variation on a drifting goals archetype (Senge 1992: 383). This is encountered in everyday life where there is a need to move from a current situation toward a vision of a new situation. The contrast between the two states creates tension that can either force one to lower the vision, do something innovative to change the current situation, or fragment the tension through (in this example) avoidance, willpower or devoting energy to other tasks (urgency).

The narrative here can have many outcomes. In a positive version, the initial vision may be lowered slightly and there will be a period of turbulence due to tension fragmentation before the current situation rises to the level of the vision. The model can be tweaked any number of ways to replicate lesser outcomes or disasters. The structure is generic and non-specific. The detail may 


\begin{tabular}{|c|c|c|c|c|c|}
\hline 1.000 & & & & Input & Output \\
\hline-1.000 & & $\vdots \quad \vdots$ & $\vdots$ & $\begin{array}{l}0.000 \\
5.000 \\
10.00 \\
15.00 \\
20.00 \\
25.00 \\
30.00 \\
35.00 \\
40.00 \\
45.00 \\
50.00 \\
55.00 \\
60.00 \\
\end{array}$ & $\begin{array}{l}0.200 \\
-0.140 \\
-0.220 \\
-0.290 \\
-0.370 \\
-0.450 \\
-0.480 \\
-0.570 \\
-0.610 \\
-0.430 \\
0.370 \\
0.110 \\
-0.120\end{array}$ \\
\hline & 0.000 & 101 & 60.00 & \multirow{2}{*}{$\begin{array}{l}\text { Data Points: } \\
\text { Edit Output: }\end{array}$} & \multirow{2}{*}{38} \\
\hline & 0.000 & & 185.00 & & \\
\hline
\end{tabular}

\section{To Equation}

Delete Graph

Cancel

OK

Figure 2. Graphic input for theme three.

be made up of endless personal 'takes' on this narrative, from the mundane to the tragic.

A playwright may use this model as the basis for triumph over the ordinary or an adverse situation, and work out specific sets, characters, plots and subplots accordingly. Each author may come up with a different story, the outcome depending on the assumptions added to drive the simulation to give graphed outputs of results. This method of modelling allows narrative artists to start the creative process from the generic idea, specific details, or a combination of both.

\section{EMOTIONAL MODELLING}

\subsection{Theoretical link}

Based on a clear semiotic scheme that is common to an intended audience, the process of mapping semiotic intention/response into the model here, and of translating this coding of emotion through the manipulation of musical thematic unity and variety, is drawn from functional film music (Gallez 1979: 47).

The idea of composers' personalising general emotional/semiotic intention/response is well established in film music theory and practice (Hagen 1972: 156-66) with innovative outcomes illustrated in much experimental film music. The approach allows creativity within a broadly agreed framework of semiotic meaning with an intended audience at a specific time and in a particular context.

In discussing the establishment of musical/emotional coding, Gorbman (1974) argues that film music functions in context by ascribing meaning by mutual implication: the music helping interpret the film and vice versa. Music in film is a signifier of emotion (Gorbman 1974: 71) or a signifier of the intuitive by expanding on the explicit nature of the visual information, allowing an audience to make a personal connection to a film.

This connection is only possible through collectively shared musical codes. Gorbman (1974) notes that cinematic musical codes, the musical encoding of emotional response for cinema, are created through being used in various guises connected with visual scenarios. i.e. there are patterns that are variations on basic cinematic archetypes that are given individual expression by composers. Yet, to be effective and make sense, cinematic codes must also rely on cultural musical codes that are prevalent outside cinema in the wider community. What a particular piece of music 'means' in implicit terms is then constantly defined by the ways that it is mediated by being embedded in a larger set of extra-musical associations.

Similarly, cultural musical coding involves paralleling musical elements with extra-musical concepts, such 


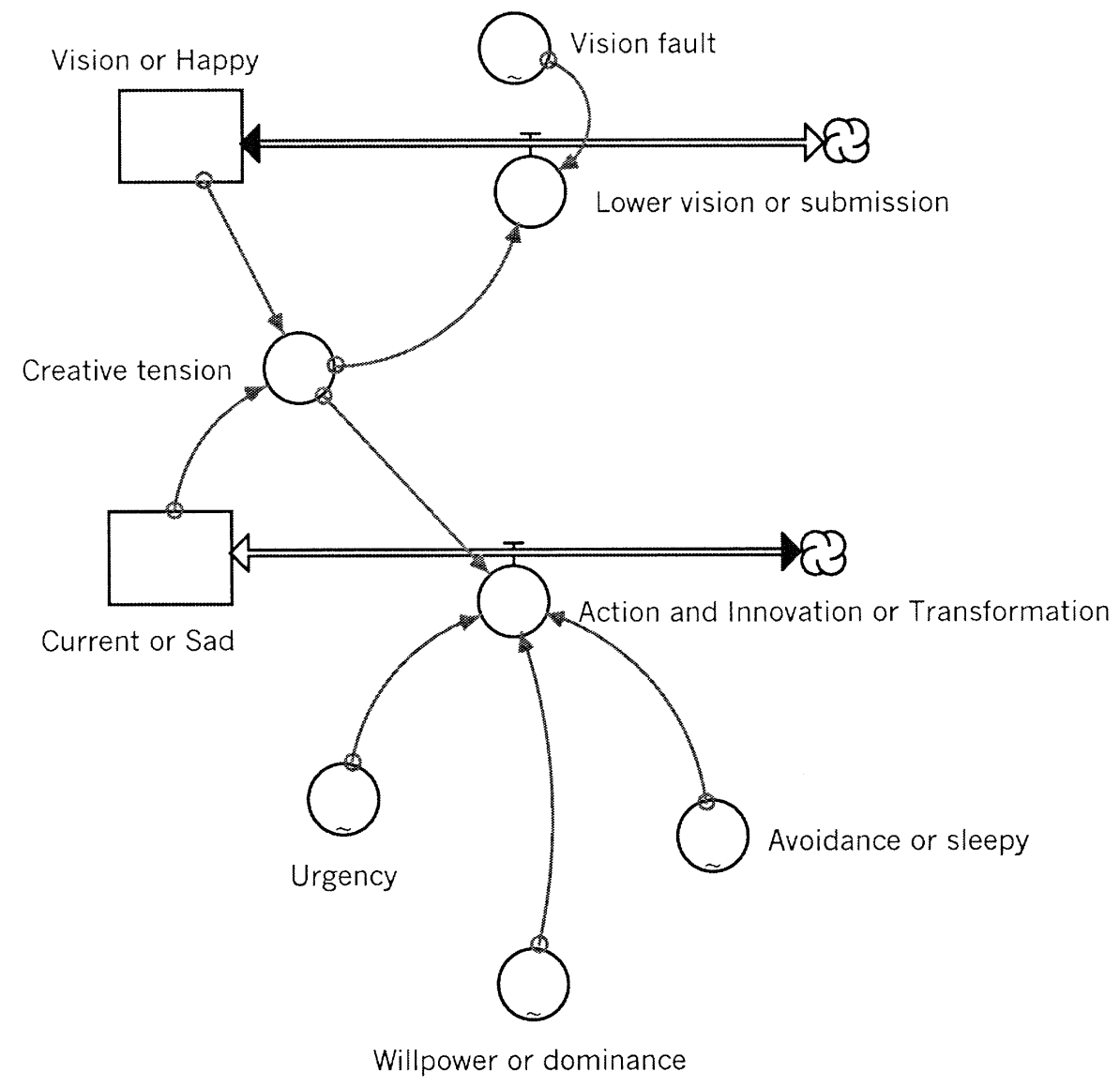

Figure 3. Everyday narrative example.

as texture in terms of tactile qualities (Meyer 1956: 136). Consequently, film music composers may write to elicit private emotional responses and denote personal feelings, but the music also reveals collective feelings as audience (Frith 1998: 136).

\subsection{Linking to system dynamics models}

As an implicit art form, music is primarily sensual rather than conceptual. To bridge this gap in the model (figure 3), conceptual notions must be translated into emotional/ aural thematic material. Using film music practice, parallel emotional states are attached to each part of the diagram (avoidance with sleepy, vision fault with submission, etc.).

Basing works on opposing poles here is taken in part from the Western dramatic art tradition of thematic juxtaposition. The narrative in figure 3 is presented with clearly juxtaposed emotional poles, for the sake of example. The encoded equivalent is based on primary emotions: aroused/interested, sleepy, sad, happy, fear/ submission and dominance/anger (Descartes 1649), although the qualitative extremes of these emotions need not necessarily be used. The mixture of these primary emotions allows the modelling of most emotional states, demonstrated in recent work modelling emotional space from audiences' reaction to music, and correlated with emotional reactions to other stimuli (Schubert 1999).

The composer is then left to translate changing moods and combinations of moods into music, as a film music composer would be required to do. A significant difference between writing for film and using system dynamics modelling as a means to generate scores is that the composer writes the structure of the narrative and controls the dynamic shape. In this sense, unlike film music composition, one becomes author, director and composer. The way that the themes respond over time in the work is dependent on their behaviour in the simulation. For example, it may be that in the narrative, avoidance (sleepy) is a strong initial response, which would result in this theme being introduced and manipulated early, and it then fading out.

What will this sound like from the generic structure given in figure 3 ? This is tantamount to asking what the exact details of a narrative play are from a generic structure; asking for specific details of a film score without knowing the intended audience to write for; or asking what the melody is if one is asked to write a slow sad eight-bar tune in triple time over I, IV, V, I. Each composer will take a different approach to the detail and the way it is unfolded, within a broadly understood framework and for a specific context. Like an author, a 
composer may start from specific sound metaphors to build a model, or from a generic structure as a form of inspiration, or a combination of these.

Regardless, once the structure and simulation are arrived at, as a playwright may break the narrative flux and points of conflict into acts, scenes and episodes, so a composer may similarly break the material into movements, sections and phrases. This episodic approach is part of the traditional craft of composition which is encouraged through this method, in contrast to the more tempting approach to simply map and translate the numerical sequence from the simulation to any number of available music software packages. Besides, the streaming approach is fraught with problems in translating data into psycho-acoustic ideas, in contrast to quickly arriving at creative solutions imaginatively.

Further, based on figure 3, a playwright may model subplots due to the interplay of parts, and a composer can auralise minor thematic developments and episodes. The output from the simulation gives very precise detail (see example in figure 4) on which to base these.

A difference between the explicit nature of a play and the implicit nature of music will mean that the happiness/sadness themes (figure 3 ) have to be first introduced as dynamic sensual ideas, rather than conceptual and static ones. A parallel is found in a novel when a 'current situation' and 'ideal situation' have to be related through linear dialogue or monologue.

\section{STRUCTURE AND METAPHOR}

For an imaginative composer or author, this approach to modelling may be sufficient to begin the compositional process. However, if a quick check of the interplay between structure and metaphor needs to be sketched to illustrate possible structural outcomes on the basis of simulated narratives, the approach is given in figure 5 .

This allows a translation from the ideational to emotional/thematic process based on more explicit psychoacoustic auralisation, as outlined in figures 1 and 2; TR stands for transformation. The inputs are taken from the way the narrative in figure 3 responds in the simulation based on the assumptions added and the resulting dialectic between generative drivers for the composition. These are mapped to the unity and variety of thematic material based on the composer's auralisations.

Milicevic (1998) argues that the ideal reception of music is neither structural nor metaphorical, but lies in the dialectic between them. Figure 5 incorporates this idea as an approach to composition based in emotion reflected in sonic symbols and structural listening. It also incorporates a bridge, through dynamic message, to an intended audience that may share implicitly the underlying story, and the possible outcomes to the story the composer wishes to express.

\section{CONCLUSION}

\subsection{What the approach is}

Of course, not all works follow the classic dynamic shape of interest, and once control of structural dynamic is gained, composers and authors often delight in playing with structural expectations. Yet, this is usually undertaken based on solid understanding of the interplay

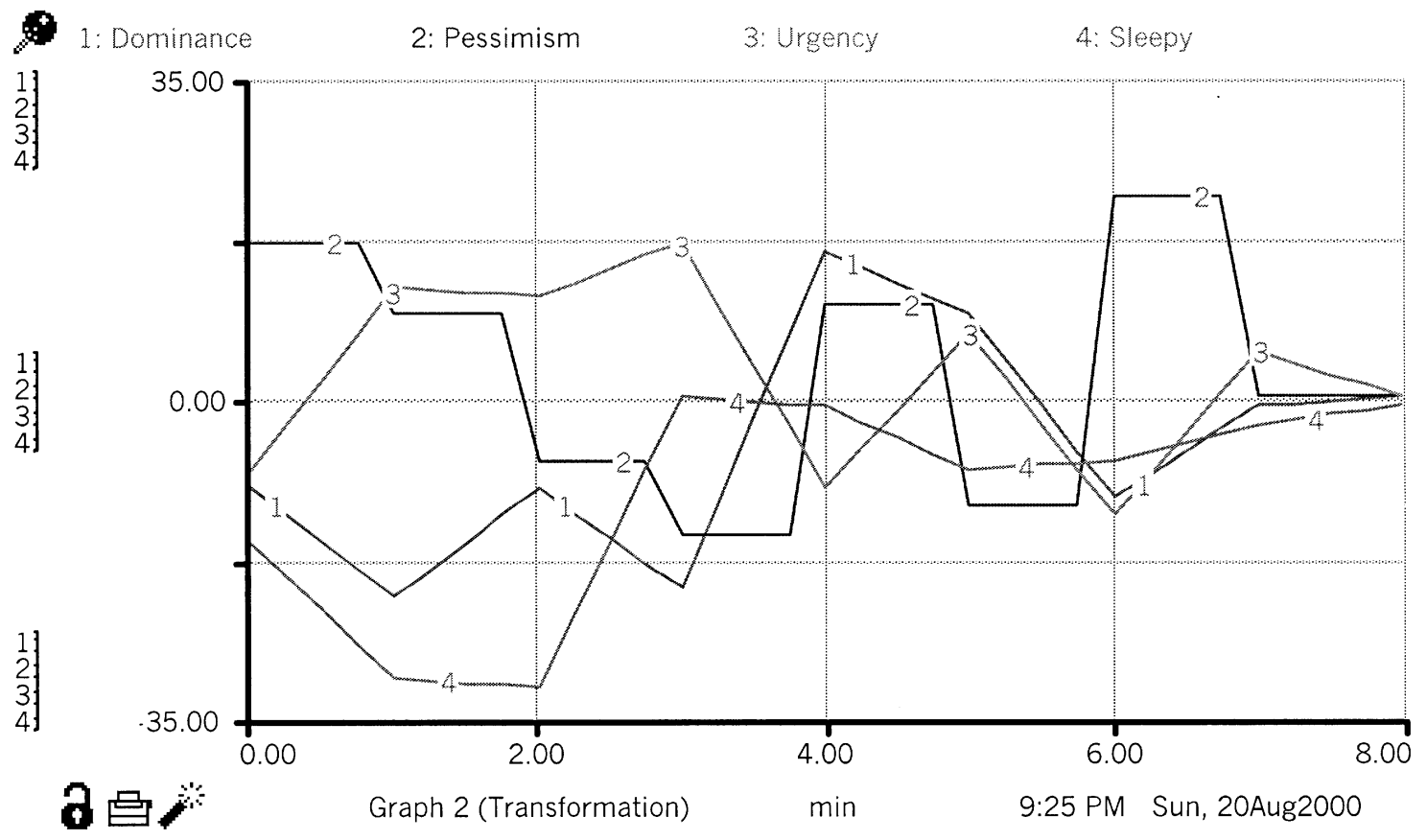

Figure 4. Graphical output of simulation of part of the structure. 


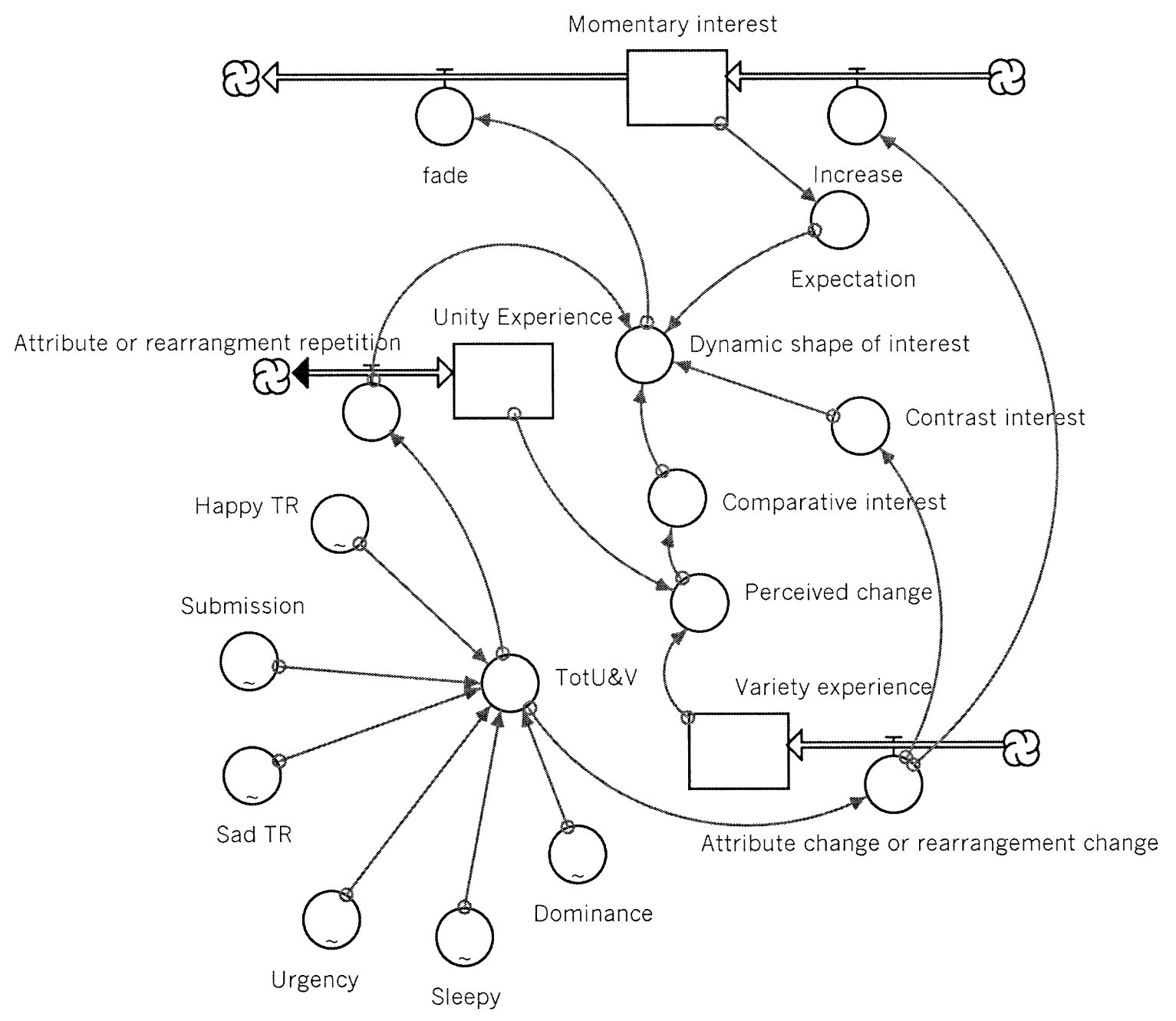

Figure 5. Emotion/theme and structure.

between the classic dynamic shape and a contrary shape being manipulated.

The counter-argument to this form of compositional control as a primary mode of communication is that musical structure is a reflection and part of the philosophical paradigm that underpins a historical world-view (Chadabe 1996), and that one approach is simply different from rather than more artistically significant than another. This argument is often used in support of much algorithmic composition being process rather than goal focused. System dynamics tools are perfectly suited to mapping and simulating process-oriented composition, if required. The alternative means of composition is a matter of philosophical choice.

System dynamics archetypes have long historical pedigrees and recur in many narrative situations. While superficially appearing to be trite formulas, the detail of individual models and their internal dialectic produce endless variety within broadly understood patterns. The balancing of the need for complexity with the requirement to communicate has ensured the continuity of the Western narrative art tradition. The ability of composers to reinvent within known archetypes is the difference between creativity and innovation (Milicevic 1998).

Using system dynamics models of narrative artistic structures that have been historically successful as a basis for current computer music composition then allows for the wisdom of the past to be combined with current practice. The example models here provide a small glimpse of the possibilities. Significantly, this approach makes an historical understanding of narrative arts and their associated techniques central to musicmaking, and a musical training central to computer music, rather than being marginalised by much computer music practice with a focus primarily on text generation at the expense of models of reception.

\subsection{What it is not}

The model presented here (figure 3) is a procedure, not a generator of specific detail. Models are meta-stories; the content must be imaginatively furnished. The limitation (and liberation) artistically is that one may have an 
idea of how something may need to change on the diagram, but not have the production skill or musical sense to translate this into sound. Similarly, one may have good structural ideas but no sense of metaphorical detail. To use an analogy from literature, there are many literary critics with a good understanding of structure and character, but who are unable to write an engaging novel. Musical craft is one thing; original ideas are sometimes another.

The method is then a tool, not an end. It is a way of visualising aspects of music that are difficult to see by other means, and affords experimentation with different approaches as an aid to structural and metaphorical expression.

\subsection{Continuing work and further information}

Current work is focussed on integrating the approach with other compositional methods and extending the models with episodic translators to illustrate differing methods of telling the underlying tale.

A good source of further information can be found at <http://www.uni-klu.ac.at/users/gossimit/links/ bookmksd.htm>, the System Dynamics / Systems Thinking Mega Link List maintained by Günther Ossimitz.

\section{REFERENCES}

Bridger, M. 1993. Narrativation in electroacoustic music and computer music - reflections on empirical research into listeners response. ICMC Proc., pp. 296-9 (Wesada).

Camurri, A. (ed.) 1998. Kansei: the technology of emotion. AIMI Int. Workshop Proc.

Chadabe, J. 1996. The history of electronic music as a reflection of structural paradigms. Leonardo Music Journal 6: $41-4$.

Cogan, R. 1984. New Images of Musical Sound. Harvard: Harvard University Press.

Coyle, R. 1993. System Dynamics Modelling: A Practical Approach. Chapman \& Hall.

Descartes, R. 1649. Treatise on the passions of the soul. In The Philosophical Works of Descartes, trans. E. Halden and G. Ross. Cambridge: Cambridge University Press (1967).

Forrester, J. 1961. Industrial Dynamics. Productivity Press.

Franks, R. 2000. Temporal elements: a cognitive system of analysis for electro-acoustic music. ICMC 2000, pp. 194-7 (Berlin).
Frith, S. 1988. Music For Pleasure: Essays in the Sociology of Pop. Oxford: Polity Press.

Gallez, D. 1979. Theories of film music. Cinema Journal 9(2): 40-7.

Gorbman, C. 1974. Unheard Melodies: Narrative Film Music. New York: Garden City.

Hagen, E. 1972. Scoring for Films. New York: Wehman.

Hopkin, P. 1992. Building Understanding in Literature. High Performance Learning Systems.

Imberty, M. 1993. The stylistic perception of a musical work: an experimental and anthropological approach. Contemporary Music Review 7: 33-48.

Kramer, J. 1988. The Time of Music. New York: Schirmer.

Landy, L. 1994. The something to hold on to factor in timbral composition. Contemporary Music Revue 10(2): 49-60.

McHugo, G. 1992. Building Understanding in Psychology. High Performance Learning Systems.

Menezes, F. 1997. To be and not to be: aspects of the interaction between instrumental and electronic compositional methods. Leonardo Music Journal 7: 3-10.

Meyer, L. 1956. Emotion and Meaning in Music. London: University of Chicago Press.

Milicevic, M. 1998. Deconstructing musical structure. Organised Sound 3(1): 27-34.

Norman, K. 1994. Telling tales. Contemporary Music Review 10(2): 103-9.

Pressing, J. 1993. Relations between musical and scientific properties of time. Contemporary Music Review 7: 105-22.

Roberts, E. (ed.) 1991. Managerial Applications of System Dynamics. Productivity Press.

Rudy, P. 1999. Music technology: two states. Sound Ideas 2(3): 16-20.

Schubert, E. 1999. Measuring emotion continuously: validity and reliability of the two-dimensional emotion space. Australian Journal of Psychology 51(3): 154-65.

Senge, P. 1992. The Fifth Discipline. The Art and Practice of the Learning Organization. New York: Random House.

Smalley, D. 1997. Spectromorphology: explaining soundshapes. Organised Sound 2(2): 107-26.

Tanzi, D. 1999. The cultural roles and communicative properties of scientifically derived compositional theories. Leonardo Music Journal 9: 103-6.

Whalley, I. 1999a. Beyond pitch/duration scoring: towards a system dynamics model of electroacoustic music. 17th Int. Conf. of the System Dynamics Society, pp. 73-83. Victoria University of Wellington.

Whalley, I. 1999b. Thematic juxtaposition and resolution in computer music: a system dynamics model. 1st Iteration Conf. in Generative Systems in the Electronic Arts, pp. 158-74. Monash University.

Zannos, I. (ed.) 1999. Music and Signs: Semiotic and Cognitive Studies in Music. Bratislava: ASCO Art and Science. 